\title{
THE EVALUATION OF CREDIT MANAGEMENT ON THE PERFORMANCE OF SMALL-SCALE ENTERPRISES IN NIGERIA
}

\author{
Abayomi Adewale Adedeji ${ }^{*}$, Joseph N. Taiwo ${ }^{2}$, Tolulope Ikumapayi ${ }^{3}$, Gbenedio \\ Akpevwe $^{4}$ \\ ${ }^{1}$ Mr. Abayomi Adewale Adedeji, Covenant University, Nigeria. Adedejiabayomi2@Gmail.Com \\ ${ }^{2}$ Dr. Joseph. N. Taiwo, Covenant University, Nigeria. Joseph.Taiwo@Covenantuniversity.Edu.Ng \\ ${ }^{3}$ Ms.Tolulope Ikumapayi, Covenant University, Nigeria.Tikumapayi@Gmail.Com \\ ${ }^{4}$ Ms.Gbenedio Akpevwe, Covenant University, Nigeria.Akpesgbens@Gmail.Com \\ Corresponding Author*
}

\begin{abstract}
This paper presents a framework for understanding the importance of credit management as it affects the performance of small-scale enterprises. Invariably credit management involves the matter of bad debts and its management. No matter how efficient managers of credit are, there is always the incidence of bad debts; evaluation of credit management therefore must involve methods of debt recovery. Credit management examines how financial institutions respond to credit facilities given to their customers and how the smallscale enterprises react to methods of credit management. Small-scale enterprises are basically grass-root businesses that support the livelihood of entrepreneurs and in turn create jobs and reduce poverty to a large extent. It is essential that credit facilities extended by the financial institution to the small-scale enterprises are properly managed in order to ensure repayment of facilities and growth of the small-scale business. This brings us to how the management of credit influences the performance of such businesses. Primary Data were utilized through the Questionnaires administered on deposit money banks, micro finance banks as well as selected small-scale business owners. Descriptive statistics were employed to analyze the data using SPSS so as to test the hypotheses. It was observed that most small-scale owners do not have the expertise to maintain proper records of their activities. Banks should enlighten their customers on importance of proper record keeping, utilization of the credit facilities given to them, and the necessity for prompt repayment of facilities. The study is expected to be useful to entrepreneurs, players in financial institutions and policy makers of the economy.
\end{abstract}

Keywords: Credit management, Small-scale enterprises, Entrepreneurs.

\section{INTRODUCTION}

Financial institutions are global phenomena, a universal institution. Banks intermediate between surplus and deficit economic units, therefore, acting as machinery for the allocation of scarce financial resources (Mohammed, 2002). Consequently, financial institutions occupy a pivotal position in the economy as it is the crux of the money market and the central nervous system of the economy. The banking industry worldwide, 
and in Nigeria particularly, have been witnessing a lot of structural changes. These changes are meant for the improvement of services for the development of its operators and for the benefit of the customers, shareholders as well as the economy at large.

Generally, banks render series of services to the economy, foremost of which is the provision of finance which has been described as a lube for economic growth (carmero, 1967). A critical factor in this growth process is adequate supply of credit to the various sectors of the economy to carry on their activities. The role of the financial institutions in this regard is that of financial intermediation which entails moving funds from the surplus unit to deficit unit of the economy, to facilitate trade and capital process. The Banking industry is positioned in such a way that its main aim is to make profit for the shareholders via providing financial services and needs to individuals and corporates bodies alike. In order to achieve this, banks accept deposits from customers and lend to others (an example in this case would be the small-scale entrepreneurs). A bank must therefore understand the importance of credit and credit management if it is to stay afloat.

Developments in the Nigerian economy in the last decade, specifically from 1992 to date have had considerable impact on the functioning of the banks and other non-financial institutions. The decade witnessed a down-hill trend in the Nigerian economy, occasional dwindling oil revenue and the global economic recession. However, banks as a sub-system of national economy was not immune to it and has since been having its own share of increased loan defaults because of the inability of borrowers to redeem their loans, this has resulted in banks distress and some have failed.

Through credit, banks promote investments and sales of a wide range of goods and services. Financial institutions in Nigeria have been performing this financial intermediation role in the economy. Thus, loans and advances today constitute a major asset of the total asset structure of banks in the country

The banking sector, in most developing economies has been segmented in terms of different institutions using varied methods to serve different customers. Loans constitute the largest assets on the financial report of most banks; revenue from loans is a significant part of the entire revenue generated within the financial year. Loans can also be described to as assets that are very delicate to banks as they have the potential of making or breaking them. For this reason, credit portfolio should be managed effectively so that it does not cause disconnect in the economy.

Lang and Jagtiani (2010), states that loan administration is a process which is designed to avoid damages to an organization as a result of events unanticipated even though possible. According to Asiedu-Mante (2011) credit management includes instituting proper rightful policies and measures that will make sure that authorities give out loans, the loans get to the right customers, and the loan is given for productive reasons which are economically viable, being thus The loan should be repaid as at when due.

\subsection{Statement of Research Problem}

Looking as far back as 1985 Shekhar (1985), provision of credit plays a fundamental role in the daily lives of people and in almost every corporation that involves any form of financial investment. The banks mainly provide credit not forgetting other services such as like currency exchange service mobilizing, deposits, local and international transfers. Hence, Credit management has a remarkable impact both at the small and macro level but for the purpose of this study we are concentrating on the micro level.

Credit management standout amongst the most critical exercises in any money related organization and can't be ignored by any financial venture occupied with credit independent of its business nature. One of the major risk faced by financial institutions relates to unrecovered credits that is unpaid loans. As indicated by (Craig, Churchill and Coster 2001), credit hazard is a specific worry for budgetary establishments in light of the fact that smaller scale loaning is unsecured (i.e., customary guarantee isn't regularly used to secure microloans). This study seeks to assess the gap in credit management performance as it particularly relates to small-scale enterprises.

Aftermath of the appropriation of Economic change program in Nigeria in the year 1981, only a few voices to change the nation's capital serious and extensive scale mechanical undertakings which depended on the rationality of import improvement to Small and Medium Scale Enterprises which have better potentials for creating local economy, subsequently producing the required merchandise and ventures that will drive the economy of Nigeria towards advancement. It depends on this preface that Ojo (2009), in his paper "Impact of Micro Finance on Entrepreneurial Development" argued that the reactions to the impediments of improvement in developing nations especially, in Nigeria, are the consolation of entrepreneurial advancement plot. Regardless of the bottomless regular assets, the nation still thinks that it is such a hard task to get things right since freedom from colonial masters. 
According to Babgana (2010) as cited in Moruf (2013), Small-scale Enterprises need financial assistance to become sustainable and competitive. These businesses play a pivotal role in economic development of the nation, in the area of employment, general development, as well as marketing of goods and services, it is important that they have access to the right facilities needed. However, the principal concern of this research is to evaluate and analyze credit management if at all, it affects the performance of small-scale enterprise in Nigeria.

These questions are expected to be answered during the process of this study

1. How effective are the monitoring and supervisory mechanisms put in place for Small-scale enterprise development?

2. To what extent does Credit management affect the performance of Small-scale Enterprises?

\subsection{Study Hypothesis}

All hypothesis was presented in their null form

$\mathrm{H}_{0}$ : Inadequate loan supervision and monitoring is not a major cause of Small-scale Enterprises bad debt.

$\mathrm{H}_{0}$ : Credit management does not affect the performance of Small-scale Enterprises.

\subsection{Significance of the Study}

A study of this nature is invaluable not only to the bank's management, share-holders, SSEs, potential investors and depositors but to the economy as a whole. To the bank's management, the study would draw their attention to the importance of assets (loans and advances) to the overall success and growth of their organizations. This spring from the truth that the proper credit management of this resource will enhance reasonable returns on shareholders' investment, this study also seeks to verify if Small-scale Enterprises performs as a result of proper credit management of intermediation activity involves accepting deposits from excess element of the economy and channeling it to the shortage of units. The act ensures proper allocation of scarce financial sources to the diverse sectors of the financial system thereby improving the overall growth and development of the economic. It's likewise expected that it will help policy makers in their determination to reform the division. Therefore, it is timely, current and relevant not only for the continued visibility of the financial system but the overall development of the nation.

This research is split into four chapters, Chapter one introduces the paper, chapter two reviews literature based on empirical review, not forgetting theoretical reviews also, Chapter three describes the methodology used in the research, analyses the data and interpretations of findings, Chapter four concludes the paper and provides recommendations where appropriate

\section{LITERATURE REVIEW}

\subsection{Conceptual Review}

\subsection{Credit Management}

Credit management refers to the overall procedure of loaning beginning from inquisitive about the prospective debtors up to recuperating the sum approved (both principal and interest). In the investment (i.e finance) sector, the management of credit facility gets crucial with critical actions for example, accepting credit requests, credit appraisal, its approval, monitoring, and of-course recovery of non-performing loans if it goes bad (Shekhar 1985). The issue of credit management has a significant complication both at the smaller scale and large scale level. At the point the facility is designated ineffectively it tends to increase expenses to lenders, dissolves the assets, and minimizes financial institutions adaptability to diverting assets towards elective exercises. In addition, the higher the facility, the higher the hazard related. The issue of advance default, comes about because of poor credit administration, lessens the loaning limit of the financial institution. Likewise restricts new candidates' entrance to the facility as the financial institutions income administration becomes problematic and fragile. However, it might bother the ordinary inflow and surge of asset.

\subsection{Procedure of Credit Management}

The procedure loan administration begins from evaluating the worthiness of the client in-terms of his repayment behavior and his business practicality. It is critical if the bank broadens or expands the credit ceiling towards a specific client. Competent credit administration looks to not just ensure the bank or any money related organization required from conceivable misfortunes, yet in addition shields the client from 
making more obligation commitments that can't be settled in an auspicious way. At the point when the procedure of credit administration works proficiently, everybody included advantages. This study considered Customer Evaluation as a variable of Credit Management.

\subsection{Customer Evaluation}

The initial phase in restricting credit chance includes putting potential applicants to series of test, this is to guarantee the eagerness and might to pay back as at when due. Most microfinance Institutions makes use of the 5 Cs of credit to evaluate a client as a potential borrower or not (Abedi, 2000). This 5 Cs help Fls to effectively give credit facilities, as the customers become subjected to the this test, they know more about the customer in terms of character, capability, capital, condition and collateral.

A credit expert regularly gives essential consideration regarding the initial two C's- character and capabilitysince it speaks to the fundamental prerequisites for stretching out the facility to a candidate. The thought of the remaining C's-Capital, condition, and collateral tends to be critical in organizing the facility and settling on its last hinge of approval, this is influenced by the loan investigator's involvement and discretion.

As indicated by Golden and Walker (1993), he identified likewise five Cs of awful obligation; that speaks to prepare for a specific end goal to help avoid issues. These are: Complacency, Carelessness, Communication-breakdown, Contingency, and Competition.

The model for scoring credit is an arrangement system that organizations assembled from applications methods for fresh or existing facility; these are used to allot potential customers to great or terrible facility risk classes (Constantinescu, Badea, Cucuci \& Ceausu 2010). Inkumubi (2009) noticed that initial capital fund as major stumbling block for business people especially small-scale businesses attempting to get capital. This is essentially applicable to little scale ventures, early business entrepreneurs that have little or no cash to use as capital; or with no collateral to be used as security for the credit facility.

\subsection{Some Problems Facing Small-Scale Enterprises in Nigeria}

According to Ekhator (2001:32), the major problems of small-scale enterprises sometimes arise from the nature and characteristics of the enterprise. He therefore classifies their problems into two main categories:

1. Problems inherent in the small enterprise.

2. Problems arising from weak official sustenance.

Babajide (2002:17) strongly opined that small-scale enterprises major problem does not primarily depend on avenues of sourcing funds but its accessibility. Even after 1970, when the government diverted from the industrialized to focus and lay pre-eminence to small and medium scale enterprises from import substitution and large scale industrialization, it has been series of promotions, financial incentives by successive governments to promote small-scale enterprises. The capitalists are also well-known and her exploits recorded cannot be equated with the drive and energy ventured into it.

Mordi (2002:35) believes that funding is not the major problems of small-scale enterprises. He prefers to view the situation from two perspectives. According to him, most small-scale enterprises find it difficult to differentiate between the owner of the business and the business itself. He said that many small business managers run the business without some shape of financial duty and show off gross lack of knowledge about the need to seek equity participation that is capable of lifting the enterprise to more heights but this is grossly neglected.

On the policy side, the fundamental problem he sees is the hassle of offering marketing protection for smallscale enterprises. He stated that the authorities do not provide market protection for small-scale companies in the country. Taking the local manufacturers into consideration, they face stiff competition from their overseas counterparts, who produce who produce beneath economy of scale that give them unfair advantage. An example is the textile industry in Nigeria. Mordi cited that the local wax industry in Nigeria was formerly satisfactory when compared to others and sold well inside the marketplace until Hollandie wax come into the its boarders and was seen as been superior or been modern in flip, it introduced decline to the rate of Nigerian wax. He stated so many other reasons to buttress his belief that fund is not the major problem because if you give funds for somebody to produce and such products are not been bought, especially when the government happens to be its largest buyer, market is not been created for him.

Another area the government can assist small-scale enterprises, is in the area of "encouraging patronage". He said that it is not simply enough for the government to champion the "produce more and buy made- inNigeria goods" crusade. He said that the government should take practical steps by patronizing small-scale enterprises to serve as morale booster. He said that a lot of keyboards used in churches and other places in 
Nigeria currently are products of small-scale enterprises in developed countries. He recalled that when some small-scale enterprises in Japan built the keyboard, the government made it compulsory for all public schools to purchase them for the purpose of learning music. Thus, enabled its manufacturers to add more beautiful notes before they were shipped to Nigeria. Small-scale enterprises expert, however, observed that the government appears to have come to grips with the situation by taking a long over-due step to ban the importation of some products such as turkey, beer, bottled water and cigarette lighters.

According to Obitayo (2001:16), small-scale enterprises like large scale enterprises assemble finished goods and depend critically on imported raw materials and equipment, and thus suffer from the same problems. But the size, characteristics and isolation of small-scale enterprises tends to make them vulnerable to these constraints which has less effect on the large ones. Hence, the small-scale enterprises tend to record a higher rate of business failure.

Despite efforts given at availing capital to small businesses and ensuring that the nation's regulatory framework is lenient with the termination of stringent policies that are hazardous to the stable growth and development of small businesses, there still remains areas that specifically have not been attended to appropriately. These areas are discussed below:

\subsubsection{Poor Access to Credit Facilities}

Finance happens to be one of the critical needs of small-scale businesses or enterprises (SSE) to establish production plants, technological advancement, larger production etc. this also has been identified as their basic problem, reflecting on the imperfect market. A lot of Small-scale Enterprises (SSEs) tend to have limited link to institutional finance, not excluding the short-term working capital to meet the ever dynamic needs. Well, since financial institutions are risk adverse, the bad performance of small-scale enterprises (SSEs) and the high risks and transaction cost commonly linked to these small scale facilities have made them (financial institutions) unlikely to lend to small-scale enterprises (SSEs).

Other limiting factors include small-scale enterprises (SSEs) and their required equity contribution, the securities needed by the financial institution to recoup loan amount in case of default, shortage of long term loans, restrictive monetary policy and high cost of borrowing. The wholesale liberalization of the financial sector and the tight monetary policy stance which addressed excess liquidity has resulted in rising interest rates on loans. The specialized target credit scheme such as NERFUND and SME I and II are some of the examples provided by the federal and different state governments but they also have encountered difficulties due to acute budgetary constraints and lack of counterpart funding and have to a limited extent, succeeded in addressing the funding requirements of small-scale Enterprises (SSEs).

\subsubsection{Infrastructure Constraint}

The pitiable state of the country's basic structure has stayed basically stagnant, and incompletely dictates the development limits of Small-scale Enterprise. Creative actions in industrial sub-division are categorized by flawed structure, relentless electricity outage and inefficiency of credit limits which adversely affect small industries. Also, the inadequacy of provision of basic amenities, such as the telecommunications, transportation, and poor water flow indicates one of the utmost lacks to small-scale industries improvement.

Most Small-scale Enterprises (SSEs), help to reserved provisioning of these facilities at great costs, thereby reducing the available funds of their actions. A World Bank contemplate (1929:3), estimated that such cost accounted for $15 \%-20 \%$ of the cost of establishing small-scale enterprises in Nigeria. It is likely to be much higher today, given the high level deterioration of the basic infrastructure. Contemporary evidence has shown that the burden of the provision of infrastructure facilities is much heavier on small-scale enterprises than the large enterprises.

\subsubsection{Technical Constraint}

Like large enterprises, small-scale enterprises (SSEs) requires current administrative abilities to source assets which are scarce in the nation., hence, the collaboration of the government and private sector ensures needed relieve schemes which primarily caters for the gap in the small-scale industry. In line with that, the National Association of small-scale enterprises (NASME), therefore has to work with the industrial development-center_(IDC) for the sole purpose of this.

\subsubsection{Troubling Macroeconomic Variables}

Tough Macroeconomic conditions in Nigeria are badly influencing the kick-off of sound Small-scale industry and are also threatening the development and growth of the small-scale businesses. Majority of Small-scale Enterprise are pondering on the element of been susceptible to the macroeconomic instability and policy 
changes. Other sources of uncertainty that have impacted negatively on small-scale enterprises include high and unpredictable inflation, price instability, foreign debt harden and service obligation.

\subsection{Theoretical Review}

\subsubsection{Credit Risk Theory}

This study adopted credit risk theory by Melton (1974); this theory was adopted by the researchers because it holds an important role in credit management. In spite of the fact that individuals have been confronting credit risk as far back as early ages, credit risk has not been critically examined until late 30 s. During the Early writing up before 1974, for a customer to be able to access a loan facility, the financial body tends to adopt a conventional actuarial strategy for credit risk. This is where significant trouble lies, in their entire believe or reliance on chronicled information. As of not long ago, there were but three quantitative methodologies of evaluating credit risk: organizational approach, diminished shape evaluation and deficient data approach. (Crosbie. 2003)

Melton (1974) announced the credit chance hypothesis generally called the structural theory which is said the default occasion gets from a company's advantage development displayed by a dispersion procedure with steady parameters. Such models are normally characterized re normally characterized "structural model" and it is based on variables related a specific issuer. An advancement of this field is spoken to by resource of models where the misfortune contingent on default is exogenously particular. In these models, the default is exogenously particular. In these models, a debt can occur all through the lifespan of a security and doesn't occur when it's due (Long staff and Schwartz 1995).

\subsection{Empirical Review}

Pyle (1997), researched on bank credit management and he discovered that banks and other financial institutions need to reach expected administrative necessities for chance estimation and capital. Be that as it may, it would be unwise to imagine that day to day business is the purpose of setting up a good hazard administration system. It was held, chiefs require dependable hazard measures to guide funding to exercises with the best hazard/compensate proportions. They require gauge of the measure of potential misfortunes to remain inside cutoff points forced by promptly accessible liquidity, by leasers, clients and controllers. They require instruments to screen positions and make motivations for judicious hazard taking by divisions and people.

Nagarajan (2001) investigated hazard administration for micro-finance establishments in Mozambique and he found out that hazard administration tends to be a dynamic procedure which preferably is created amid typical circumstances and tried in the wake of hazard. This allows cautious arranging and responsibility on part of all partners. Urging to take note, that it is conceivable to limit dangers related misfortunes via persevering administration of portfolio and income, by providing hearty and sound institutional framework with talented and skilled HR thereby instilling wonderful customer interaction, via powerful relationship with partners.

Achou and Tenguh, (2008) additionally led look into on bank execution and credit chance administration found that there is a noteworthy connection between money related foundations execution as far as productivity) and credit hazard administration. Good loan hazard administration spurs better judgment. In this manner, it is of pivotal significance that budgetary foundations hone good credit hazard administration and shielding the benefits of the organizations and ensures financial specialists "interests. This is additionally valid for small-scale back organizations. Strategy utilized by the scientists is blended research technique.

Credit hazard radiates from the way banks manage people, corporate, money related bases or supreme materials. A poor portfolio may haul in fluidity and also credit chance. The point of credit hazard administration is to amplify a bank's chance balanced rate of return by keeping up credit chance introduction inside adequate limit. The effective administration of credit chance is a key piece of the general hazard administration framework and is essential to each bank's base and in the long run the survival of all managing an account foundation. It is in this way critical that credit choices are made by sound investigations of dangers required to maintain a strategic distance from damages to bank's gainfulness. They held powerful management of credit risk is a primary part of a far reaching strategy to chance management and primary to the long achievement of all saving money organizations.

Sindani (2012) investigated the "Effectiveness of credit Management System on Loan Performance: Empirical Evidence from Micro-Finance Sector in Kenya ", discovered that the Credit detailed from Microfinance establishments do influence advance implementation; contribution from credit manager and officer alike and clients in defining credit conditions influences advance implementation. Funding costs 
indicted negatively affected the implementation of the credits, the greater the funding costs the lower the advance execution.

Brewer (2007) perceives that loaning to small firms is tough as a result of the issues of data asymmetry. However, inventive approaches in discussing the problems have the tendency to increase credit accessibility to the organizations. The two diverse advancements in small business financing are; improved use of credit scoring innovation and the presentation of microfinance loaning organizations. In spite of the fact that these two methodologies make utilization of various advancements, they give a profitable picture of how loaning to small firms is developing after some time.

Olomola (2002) discovered that reimbursement is altogether influenced by borrower's attributes, moneylender's qualities and advance qualities. Reimbursement issues can be in form of credit misconduct and default. Whatever the procedure be that as it may, the borrowers alone can't be considered mindful wherever issues emerge, it is vital to look at the degree to which the two borrowers and moneylenders consent to advance contract and also the nature and obligations, duties and commitments of the two gatherings as reflected in the outline of the credit program instead of stacking faults just on the borrows

According to prior studies as discussed earlier in this section. It was discovered that most investigation so far are especially arguing about the advance recuperation issues, determinant factors for lack of repayment by borrowers in monetary establishments is common in small-scale lending. Having likewise seen in the survey of academic writing that there is no research piloted to evaluate the effectiveness of credit management in the performance of small scale enterprises which is seen as a major catalyst of economic development. Hence the justification for carrying out this study "THE EVALUATION OF CREDIT MANAGEMENT IN THE PERFORMANCE OF SMALL-SCALE ENTERPRISES IN NIGERIA" to conform whether financial institutions are really managing credit as it is to be managed, if the small-scale enterprises are been given a chance of survival in the accessing of funds to thrive, if truly thorough credit management aids the performance of the small-scale businesses thus identifying credit management issues and accordingly to prescribe strategies that are accepted to advance quality advance development and shorten non-execution.

\section{METHODLOGY}

This research design adopted the use of primary data, a well-designed questionnaire was developed. The questionnaire was designed in a way in which the objective of this study was considered. Primary data was used in this study because it involves, collection of data administered to both staff and customers (business owners) of selected deposit money bank and microfinance banks. The Information composed from the survey were analyzed, interpreted and summarized, accordingly. This research adopted the use of closed ended questionnaire. The questionnaire was composed with 5 Likert scale and comprising of few important inquires to the study. The questionnaire was designed in a precise manner to attract desired response; it was structured in two sections; Section A contained the personal information of the respondent while section $B$ contains information regarding the aim and objective for carrying out this research.

\subsection{Data Analysis}

\subsubsection{Descriptive Statistics of Hypothesis 1}

In order to test this hypothesis, the questions generated were administered to the staff of a selected financial institutions located within Ogun and Lagos State in Nigeria. These states were selected because of their proximity to the researchers. A total of 200 questionnaires were administered and 150 questionnaires were returned properly filled. Shown below are the mean and standard deviation of cumulative respondents

\begin{tabular}{|l|l|l|l|}
\hline Hypothesis 1 & Total respondents & Mean & Standard deviation \\
\hline $\begin{array}{l}\text { Inadequate loan } \\
\text { supervision and } \\
\text { monitoring is not a } \\
\text { major cause of } \\
\text { Small-scale } \\
\text { Enterprises bad debt }\end{array}$ & 150 & 25.2533 & 8.79273 \\
\hline
\end{tabular}

Figure 1: Field Survey 2017

From fig 1 , the standard deviation of 8.79273 shows that the observations were spread within 3 standard deviation on each side of the mean. 
Staffs of Financial institutions agree that inadequate loan supervision and monitoring is not a major cause of Small-scale Enterprises bad debt. Based on the findings of the survey carried out $63 \%$ of respondents agreed that they ensure that funds made available to SSE are utilized for the sole purpose of their respective businesses and $67 \%$ of the respondents acknowledged the practice of regular visitation to SSE customers to ensure proper monitoring. However, based on the respondents only $27 \%$ of the SSE customers repay their loans as at when due. This could be as a result of mismanagement of funds or lack of proper books of account being kept or even as a result of operational negligence of their business.

\subsubsection{Descriptive Statistics of Hypothesis 2}

In order to test this hypothesis, the questions generated were administered to the customers of the financial institutions particularly Small-scale Enterprises or Entrepreneurs within the selected located within Ogun and Lagos State. A total of 300 questionnaires were administered and 200 questionnaires were returned properly filled. Shown below are the mean and standard deviation of cumulative respondent.

\begin{tabular}{|l|l|l|l|}
\hline Hypothesis & Total respondents & Mean & Standard deviation \\
\hline $\begin{array}{l}\text { Credit management } \\
\text { do not affect the } \\
\text { performance of } \\
\text { Small-scale } \\
\text { Enterprises }\end{array}$ & 200 & 28.675 & 10.9946 \\
\hline
\end{tabular}

Figure 2: Field Survey 2017

From fig.2, the standard deviation of 10.9946 shows that the observations were spread within 2 standard deviations on each side of the mean. Based on the survey carried out $60 \%$ of the SSE respondents are of the opinion that the credit facilities obtained from financial institutions have helped improved their businesses. $60 \%$ of the respondents are also of the opinion that the success of SSEs lays in the collaboration between financial institution and SSEs. This collaboration could be in form of financial advisory service especially in the areas of management and investment of funds or easier means of transacting business-like introduction of POS machines and internet banking.

Furthermore, $73 \%$ of the staff of the financial institutions and $62 \%$ of SSEs respondents agrees that regular training of credit officials and good governance put in place are key indicators for effective credit management.

\section{CONCLUSION AND RECOMMENDATIONS}

From the findings, the study found that inadequate loan supervision and monitoring is not a major cause of Small-scale Enterprises bad debt and also that credit management affects the performance of small-scale enterprises. The study revealed that inability for some small-scale enterprises to pay outstanding facilities as at when due could be as a result of result of mismanagement of funds, lack of proper books of account being kept or even the frequent method of transacting business based on Cash payment.

How effective financial institutions manage the credit given to small-scale businesses determine the performance of such businesses. The process of appraisal, the process of effectively identifying small businesses that genuinely need credit facility and ensuring the funds are been utilized for that same purpose must be the primary duty of the credit managers or credit staff of financial institution.

It is said that small businesses are catalyst for economic development. This study hereby recommends the need to regularly train credit managers, staff and workers on the methods on appraisal techniques so as to be able to identify entrepreneur's worthy of receiving and utilizing credit for business purpose, and this process in turn reduces non-performing loans. It is also important for the credit staff to be equipped enough to provide their clients especially small-scale entrepreneurs with financial advice regarding keeping proper books of records.

There is also need for the financial institutions to introduce modern and easier ways for doing business like the point of sale(POS) to these small-scale business so the issue of misappropriation of funds or too much cash in hand will be reduced to the barest minimum and also hasten the pace of doing business. 


\section{REFERENCE LIST}

Abedi, S. (2000). Highway to Success, Credit Management Journal. http:// leatherspinters.com

Achou, T. F., \& Tenguh, N. C. (2008). Bank performance and credit risk management (Unpublished Master's Thesis). University of Skovde, Sweden.

Asiedu - Mante, E. (2011). Rural Banking in Ghana, Combert Impression, Accra.

Babagana, S. A. (2010). Impact assessment of the role of micro finance banks in promoting small and medium enterprises growth in Nigeria. journal of economic development, 65, www.icidr.com

Babajide A.K. (2002). "Funding of SME: Sourcing of Funds and Problem Limiting Access." Paper Presented at the 4th Partners Forum of the Public Practice Section of the Institute of Chartered Accountants of Nigeria (ICAN), 17

Brewer, Elijah III (2007). "One Lending to Small Firms" Journal of Small Business Management, 45 (1), 4546

Constantinescu, A., Badea, L., Cucui, I. \& Ceausu, G. (2010). Neuro-Fuzzy Classifiers for Credit Scoring. Proceedings of the 8th WSEAS International Conference on Management, Marketing and Finance, 132-137.

Craig, C., \& Dan, C. (2001). Care Microfinance Risk Management Handbook. Available online: http://www.adb.org/doc./books/interest.

Crosbie , (2003) Journal of Planktonic Research, plankt.oxfordjournals.org/content

Ekhator, V.E. (2002). Role of Small and Medium Scale Enterprises in the Nigerian Economy. Paper Presented to the Department of Public Administration, University of Abuja.

Golden., \& Walker, (1993). Corporate Governance in the financial Institutions. Journal of Business Finance and Accounting,16(3), 385-398

Inkumbi, M. (2009). Beyond the 5Cs of Lending (online) Available http://www.dbn.com(05/07/2013)

Lang. W. \& Jagtiani, J. A. (2010). The Mortgage and Financial Crises: The Role of Credit Risk Management and Corporate Governance, Atlantic Economic Journal, 38, 295- 316.

Longstaff, F., \& Schwartz, E. (1995). A simple approach to valuing risky fixed and floating rate debt. Journal of Finance, 50, 789-819.

Mohammed, A, (2002). The Dynamism of the banking industry: Research Report

Mordi, F. (2002). "Why Government Must Protect Small and Medium Scale Enterprises". Financial Standard, August 19.

Nagarajan, G. (2001). Can Microfinance Meet the Poor's Needs in Times of Natural Disaster? Microenterprise Best Practices (Bethesda: Development Alternatives, Inc).

Obitayo, K. M. (2001). "Creating an Enabling Environment for Small-scale Industries" Paper Presented at the Workshop on SMEs Financing, Organized by the Chartered Institute of Bankers of Nigeria.

Ojo, O. (2009). Impact of Micro Finance on Entrepreneurial Development: A case of Nigeria. A paper presented at the International Conference on economic and administration, organized by the faculty of Administration and Business, University of Bucharest, Romania, 14th -15th November, 2009.

Pyle, D. H. (1997). Bank Risk Management: Theory, Institute of Business and Economic Research, University of California, Finance Working Paper No. RPF-272, July 1997.

Olomola, S. (2002) Determinants of small holder loan repayment, performance, Evidence, Nigerian Microfinance system, Nigeria.

Sindani, R. (2012). An overview of fraud and money laundering in the East Africa financial services industry. Nairobi: Deloitte Forensic.

Shekhar K.C. (1985) Banking Theory and Practices, New Delhi: Vikas Publishing house pvt, Ltd. 